\title{
Measuring the local wind field at an escarpment using small remotely-piloted aircraft
}

\author{
Norman Wildmann*, Sarah Bernard, Jens Bange \\ Eberhard Karls University Tübingen, Center for Applied Geoscience, Hölderlinstr. 12, 72074 Tübingen, Germany
}

\section{A R T I C L E I N F O}

\section{Article history:}

Received 29 October 2015

Received in revised form

15 August 2016

Accepted 30 October 2016

Available online xxx

\section{Keywords:}

Wind energy

Complex terrain

Remotely-piloted aircraft

Unmanned aerial vehicle

Wind potential

\begin{abstract}
A B S T R A C T
A remotely-piloted aircraft (RPA) is used in this study to collect high resolution data of the flow in complex terrain at a potential site for a wind energy test field in Southern Germany. It is described how such a system was used to retrieve information about the flow field, turbulence intensity, vertical wind components and shear at an escarpment site that is known for its high wind potential. Measurements were done with the aircraft on several days with varying wind and weather conditions, while the focus of the study is on the characterisation of the flow field in main wind direction and neutral stratification. It is shown that flow inclination of up to $30^{\circ}$ is found over the escarpment, but attenuates within a few hundred metres downstream. The formation of a reattached boundary layer could be measured, as well as an increased turbulence intensity in the reattachment zone. The results are highly valuable information for the planning of a wind energy test site at the location of the experiment and can also be used for the validation of numerical simulations and remote sensing instruments.
\end{abstract}

(C) 2016 Elsevier Ltd. All rights reserved.

\section{Introduction}

The German government has made sustainable energy a high priority social task in the 21st century, and this requires highefficiency renewable energy technologies which can compete economically with nuclear and fossil-fuel energy resources. Wind energy is of primary importance for renewable electricity generation and large investments are being made in the field. Without considering political and social aspects of wind farm siting, recent studies show that large wind potential does not only exist offshore, but also onshore, and even in the Southern federal states of Germany [1]. Generating energy close to the consumer reduces the necessity to strengthen the electric-line system. In the federal state of Baden-Württemberg, the best potential sites for wind energy are found in complex terrain, i.e. in the Black Forest, or the Swabian Alb. While the wind flow over simple geometries like a forward-facing step [2,3], or a sine-shaped hill [4] can be modelled and mathematically described, wind flow in complex terrain is not well understood, and it is not easy to model or predict without the help of advanced computational fluid dynamics (CFD) simulations. Even

\footnotetext{
* Corresponding author.

E-mail address: norman.wildmann@dlr.de (N. Wildmann).

URL: http://www.geo.uni-tuebingen.de/umphy
}

though these simulations are advanced tools that can even resolve turbulence to a certain degree with the help of large-eddy simulation (LES), an initialisation and validation of the results is essential. Rokenes and Krogstad [5] have done an extensive wind tunnel study about the flow over a generic model of the mountainous terrain at the Norwegian coastline and were able to show flow speed-up, flow separation and turbulence distribution for different scenarios. So far, validation of these kind of experiments in the real world has not been possible with an adequate level of detail to verify the simulations and wind tunnel experiments. Common practice to measure the wind flow that the turbine experiences with a single upstream meteorological tower is insufficient for a wind flow that is horizontally heterogeneous and strongly depending on the wind direction. Lidar instruments, that have become increasingly popular for wind-energy research have weaknesses in complex terrain, because they assume a homogeneous wind field and a negligible vertical wind component [6]. Only recently, methods to retrieve the three-dimensional wind vector from lidar data have become popular in wind-energy research, but they require a high investment in at least three synchronously scanning instruments and provide a spatial average of several tens of meters [7-9]. A promising tool to investigate smallscale inhomogeneities and processes in the atmospheric boundary layer (ABL) are remotely-piloted aircraft (RPA), also known as unmanned aerial vehicles (UAV). Using these platforms as sensor 
carrier for fast-response thermodynamic sensors, it is possible to acquire atmospheric data with sub-meter resolution, covering areas up to one square kilometer in all heights relevant to wind energy and boundary-layer meteorology in general [10-13]. The high spatial resolution even allows to investigate and quantify small-scale turbulence, which is increasingly in the focus of turbine-load research [14]. In several projects, the possibility to use RPAs for wind-energy research has already been explored. The studies by Giebel et al. [15], Reuder et al. [16], Subramanian et al. [17] and Wildmann et al. [12] did all use RPA to evaluate the possibilities to study inflow and wake of wind turbines. In the framework of the projects KonTest and Lidar Complex, initiated by the research initiative WindForS (www.windfors.de), a RPA was applied to investigate the wind flow over an escarpment in the Swabian Alb. The data that was collected on more than ten experiment days gives valuable insight into the flow distortion that is caused by the escarpment and the effects downstream, at a site that is currently considered for the installation of a wind energy test field.

\section{Experiment description}

The focus of this work is on studying the flow at a potential wind energy test site in complex terrain using in-situ measurements from a RPA. In this section, the location of the experiment, and the meteorological instruments that were used during the experiment are described in detail.

\subsection{Location}

The location that was chosen for the experiment and is also considered for a wind energy test site is located along the so-called 'Albtrauf', a long stretched mountain ridge in the Swabian Alb in Southern Germany. The main feature of the site is an escarpment of $270 \mathrm{~m}$ height with respect to the valley. The first $100 \mathrm{~m}$ from the top are characterized by a very steep slope of up to $40^{\circ}$ and are almost fully covered with forest. Further West, the escarpment smooths out into a more gentle slope of heterogeneous land-use down into the river valley. The edge of the Albtrauf is not straight, but curved in a complex shape. At the location of the test site, the wind direction normal to the crest is approximately $300^{\circ}$ (compare Fig. 1). Since considerably higher average wind speeds are found on top of the escarpment with respect to the valley, the site already features nine wind energy converters (WEC), which makes it one of the largest wind farms in the federal state of Baden-Württemberg. All of the already present WECs are placed with more than $1 \mathrm{~km}$ distance to the escarpment. The focus of the measurements in this experiment are in closer proximity, over the crest, and upstream the escarpment, in order to get a full picture of the flow distortion. What makes the site particularly interesting for wind-energy research is the fact that the main wind direction is West-NorthWest (see Fig. 1), which is perpendicular to the escarpment. There are some considerable orographic features upstream the escarpment, which could have an influence on the wind flow depending on the incoming wind direction within a very narrow angular band. Fig. 2 shows the terrain profile in three different directions.

\subsection{Instruments}

While the focus of this work is on the analysis of measurements by an RPA, there are more instruments installed on site, which could also be used to gain auxiliary information about the meteorological conditions on some of the campaign days and will be increasingly used in future campaigns. Table 1 gives an overview of all flight days, and the auxiliary measurements that were available. Flight days that were not considered for further analysis in this study, because the main wind direction was not met, or the wind speeds were too low, are shaded gray.

\subsubsection{Multipurpose airborne sensor carrier}

The multipurpose airborne sensor carrier (MASC, see Fig. 3), which has been operated by the University of Tübingen since 2012, is a fixed wing remotely piloted aircraft with wing-spans from 2.60

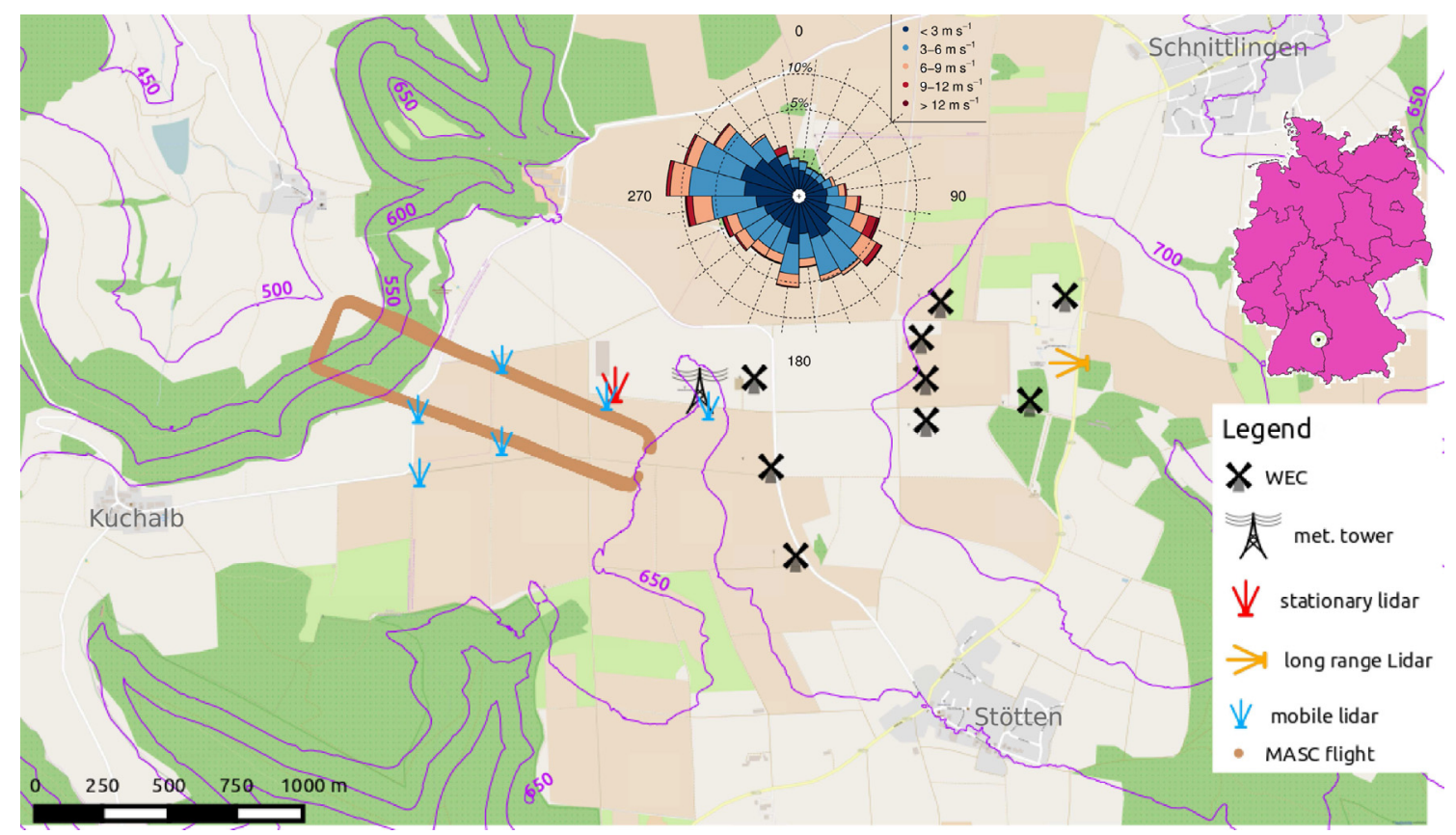

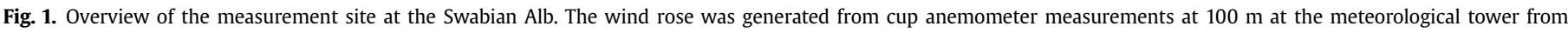

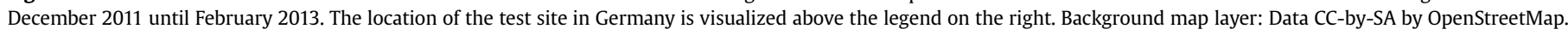




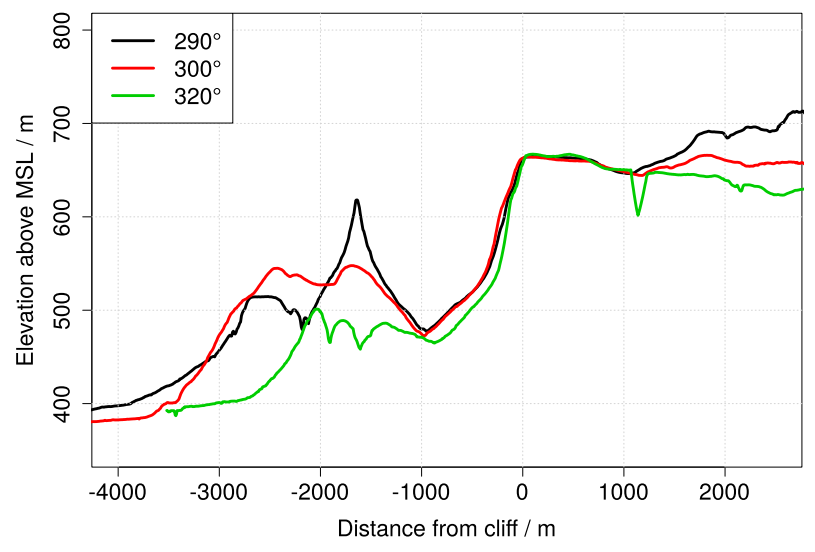

Fig. 2. Terrain profile in three different directions.

Table 1

List of flight experiments with number of flights (NoF), start and end time of the experiment, mean wind direction $\bar{\varphi}$ and mean wind speed $\overline{\mathrm{u}}$ on each day. The table also shows, which other instruments were operational on each day. The abbreviations are: tower high resolution (THR) for the sonic anemometers on the meteorological tower; tower low resolution (TLR) for other instruments on the tower; mobile lidar (ML); stationary lidar (SL) and vertical profiles with the RPA at the valley site (VP).

\begin{tabular}{|c|c|c|c|c|c|c|c|c|c|c|}
\hline \multirow[t]{2}{*}{ Date } & \multirow{2}{*}{$\frac{\mathrm{NoF}}{\#}$} & \multirow{2}{*}{$\frac{\text { Start }}{\text { UTC }}$} & \multirow{2}{*}{$\frac{\text { End }}{\text { UTC }}$} & \multirow{2}{*}{$\frac{\bar{\varphi}}{\operatorname{deg}}$} & \multirow{2}{*}{$\frac{\overline{\mathrm{u}}}{\mathrm{m} \mathrm{s}^{1}}$} & \multirow[t]{2}{*}{ THR } & \multirow[t]{2}{*}{ TLR } & \multirow[t]{2}{*}{ ML } & \multirow[t]{2}{*}{ SL } & \multirow[t]{2}{*}{ VP } \\
\hline & & & & & & & & & & \\
\hline 23 June 14 & 3 & 09:30 & $12: 00$ & 270 & 6 & & & & $\checkmark$ & \\
\hline 4 July 14 & 4 & $07: 30$ & $11: 30$ & 180 & $\leq 5$ & & & & $\checkmark$ & \\
\hline 16 July 14 & 5 & 09:00 & $11: 30$ & 270 & $\leq 3$ & & & & $\checkmark$ & $\checkmark$ \\
\hline 31 July 14 & 4 & 08:30 & $12: 00$ & diff & $\leq 3$ & & & & $\checkmark$ & \\
\hline 19 Feb 15 & 5 & $11: 00$ & $14: 30$ & 200 & $\leq 5$ & & & & $\checkmark$ & $\checkmark$ \\
\hline 5 March 15 & 4 & $11: 00$ & $14: 30$ & 320 & 5 & & $\checkmark$ & & $\checkmark$ & \\
\hline 27 March 15 & 4 & $11: 00$ & $16: 00$ & 290 & 8 & $\checkmark$ & $\checkmark$ & $\checkmark$ & $\checkmark$ & $\checkmark$ \\
\hline 1 April 15 & 9 & $10: 30$ & $15: 30$ & 290 & $\leq 10$ & $\checkmark$ & $\checkmark$ & $\checkmark$ & $\checkmark$ & $\checkmark$ \\
\hline 22 April 15 & 4 & $11: 00$ & $15: 00$ & 300 & 7 & & & $\checkmark$ & & \\
\hline 7 May 15 & 5 & $08: 30$ & $14: 00$ & 290 & 6 & $\checkmark$ & $\checkmark$ & & $\checkmark$ & $\checkmark$ \\
\hline 28 May 15 & 5 & 09:30 & $15: 00$ & 290 & 5 & & & & & $\checkmark$ \\
\hline
\end{tabular}

to $3.40 \mathrm{~m}$, a weight between 5 and $8 \mathrm{~kg}$ and a flight time up to $90 \mathrm{~min}$, all depending on payload and battery configuration. Controlled by the ROCS autopilot, which was developed at the Institute of Flight Mechanics and Control at the University of Stuttgart, the cruising airspeed of the RPA for the given experiment is $25 \mathrm{~m} \mathrm{~s}^{-}{ }^{1}$, and the aircraft will fly predefined waypoints with high precision in altitude and airspeed [12]. For the purpose of thermodynamic measurements, the MASC can be equipped with a sensor suite that features fast-response temperature sensors [18], high resolution wind vector measurements [19], as well as measurements of atmospheric humidity [20], and barometric pressure. The wind measurement is performed by measuring the flow speed and flow angles at the aircraft nose with a multi-hole flow probe, as well as the aircraft's motion and orientation in the geodetic coordinate system with an inertial measurement unit (IMU). Given the information of these sensors, wind can be calculated as

$\mathbf{u}=\mathbf{v}_{\mathbf{g s}}+\mathbf{M}\left(\mathbf{v}_{\text {tas }}+\boldsymbol{\Phi}\right)$

with wind vector $\mathbf{u}$, ground speed vector $\mathbf{v}_{\mathbf{g s}}$, airspeed vector $\mathbf{v}_{\text {tas, }}$ rotation matrix $\mathbf{M}$ from aircraft fixed coordinate system to geodetic coordinate system and a lever $\operatorname{arm} \boldsymbol{\Phi}$ between IMU and flow probe. A detailed description of wind measurement with RPA, including an error estimation can be found in van den Kroonenberg et al. [10]. Typical magnitude of errors in wind speed for the type of sensors as is used in MASC is of the order of $\pm 0.5 \mathrm{~m} \mathrm{~s}^{-1}$.

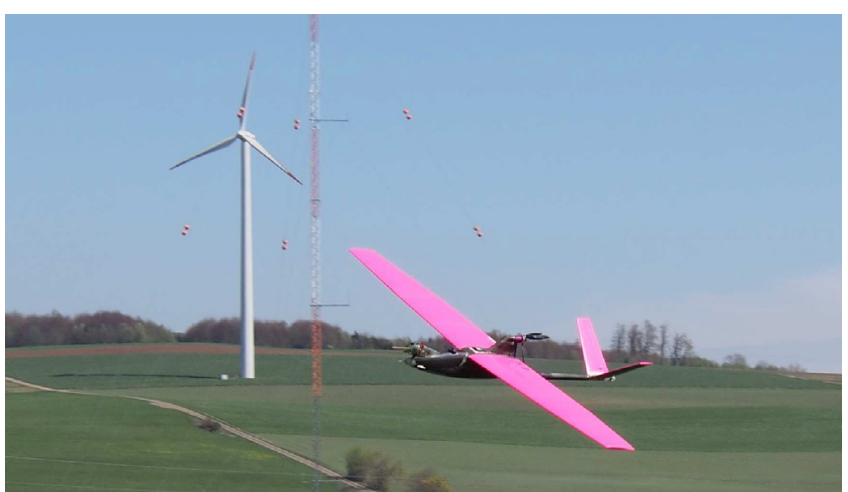

Fig. 3. The multipurpose airborne sensor carrier (MASC) in flight at the measurement site, in front of the meteorological tower and an already installed WEC.

\subsubsection{Other measurements}

As shown in Fig. 1 and Table 1, other measurements, i.e. lidar and tower measurements, were available on parts of the campaign days, but not all of them. The measurements of all systems, including the RPA, agreed within the typical accuracy of the instruments on all days, as has also been shown for meteorological measurements with RPA in multiple other studies $[11,12,18]$. Since the availability of the measurement tower and the lidar was not continuously given during the experiment, it was decided for this study to not use the data of these instruments for scaling and further analysis of the RPA data, because it would significantly reduce the available data and alternative scaling methods were developed as described in Sect. 3.2. The methods to analyse the measured data is described hereafter.

\section{Methods}

\subsection{Flight strategy}

For the purpose of measuring the three-dimensional flow field over the escarpment at the test site, a vertical grid of racetrack flight pattern in main wind direction in vertical steps of $25 \mathrm{~m}$ was performed (see Fig. 4 for a three-dimensional view of the flight pattern). At each height, two racetracks are successively flown. The lowest flight height was $60 \mathrm{~m}$, because the visibility of the RPA is strongly obstructed by trees at the crest of the escarpment if lower heights are flown. Although the RPA operates automatically, only flights within line of sight are allowed due to air traffic regulations. The highest flight level was $300 \mathrm{~m}$ in order to cover all heights that are relevant for wind energy. The racetracks extend up to $200 \mathrm{~m}$ west of the escarpment and downstream almost to the position of

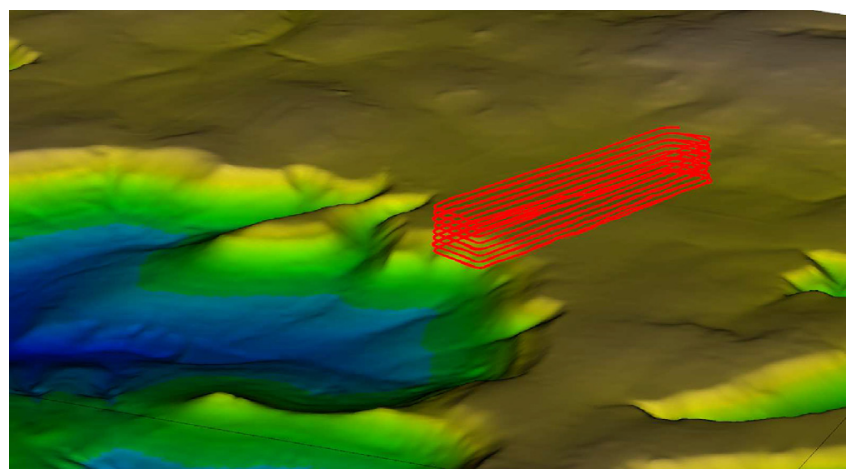

Fig. 4. Flight path for investigation of the flow field over the escarpment. 
the meteorological tower. On 27 March, 7 May and 28 May, additional to the flights over the escarpment, the RPA was deployed in the valley, almost $5 \mathrm{~km}$ West of the main site, in order to capture a vertical profile of the undisturbed airflow in the river valley. These vertical profiles reach up to $500 \mathrm{~m}$ above ground level (a.g.l.), which corresponds to approximately $200 \mathrm{~m}$ over take-off level at the main site.

\subsection{Normalization and averaging of wind measurement}

It is the goal of the study to identify areas where a considerable speed-up of the flow, flow separation or recirculation is found in the heights that are relevant to wind-energy production. Since the highly dynamic flow field over the escarpment is never sufficiently sampled in one single measurement flight, normalization of the collected wind data needs to be carried out, to be able to average all single flights, and achieve a higher statistical significance. Possible normalization could be done against the upstream undisturbed flow measured at the valley site with a second RPA. Unfortunately such measurements are not available for all measurement days. Also, none of the auxiliary instruments was operational on all campaign days. Thus, the only possible normalization that can be done to all flight days is to normalize against the average wind speed in a single flight. Despite the practical reasons for this averaging method, it has the advantage that the reference wind speed is an average of the flow in the area of interest for the time of interest, therefore no spatial or temporal differences between the data need to be considered. If all wind measurements within one $30 \mathrm{~min}$ flight are normalized by the mean wind speed in that particular flight, the change of wind speed due to mesoscale effects and synoptic scale atmospheric circulation is eliminated. The flow field however also depends on the wind speed and wind direction, so that the result of the analysis is no universal picture of the flow field, but an average of the fields of all flights in slightly different conditions. To estimate the average flow field, only East-West flight legs are considered, because the aircraft flying at constant airspeed will fly slower with respect to the ground in head wind conditions and can thus sample more data points in the same distance. For the analysis of the mean flow, $40 \mathrm{~m}$ were chosen as the width of each averaging bin. In each spatial bin, data from all racetracks are averaged. The normalized wind-speed amplification coefficient is calculated as
$A(x)=\frac{\frac{1}{n} \sum_{i=0}^{n-1} u\left(x_{i}\right)}{\bar{u}_{f}}=\frac{\bar{u}(x)}{\bar{u}_{f}}$

with $n$ the number of data points in the bin, $x$ the center location of the bin, $u(x)$ the measured wind speed at location $x, x_{i}$ the location of the aircraft for data point $i$ of the bin, $\bar{u}_{f}$ the average wind speed of one full flight and $\bar{u}(x)$ the average wind speed in the $40-\mathrm{m}$ bin centred around $x$.

\subsection{Turbulence parameter}

The typical turbulence parameter, which is considered in the design process of a WEC according to [21], is the turbulence intensity, defined as

$I=\frac{\sigma_{u}}{\bar{u}}$

with the standard deviation of the horizontal wind $\sigma_{\mathrm{u}}$ and the mean horizontal wind speed $\overline{\mathrm{u}}$. Usually, this parameter is estimated as a 10 min average of a point measurement, when cup anemometers are used for the wind measurement. Since this is not practical for RPA measurements, the averaging window is defined as a spatial bin of $40 \mathrm{~m}$ as is also used for the analysis of the mean flow. Larger eddies will not be considered this way, but the turbulence due to flow separation should be well captured and a fine spatial resolution will be achieved.

\section{Results}

Given the flight measurements of five days with comparable wind speed and wind direction, the main features of the flow can be analysed with regards to the attributes that are most interesting for wind-energy production in complex terrain, i.e. local wind-speed distribution, turbulence intensity, wind shear and vertical wind components.

\subsection{Speed-up over the escarpment}

With the normalization as described in Sect. 3.2, the flow field can be visualized as shown in Fig. 5. The figure shows two-

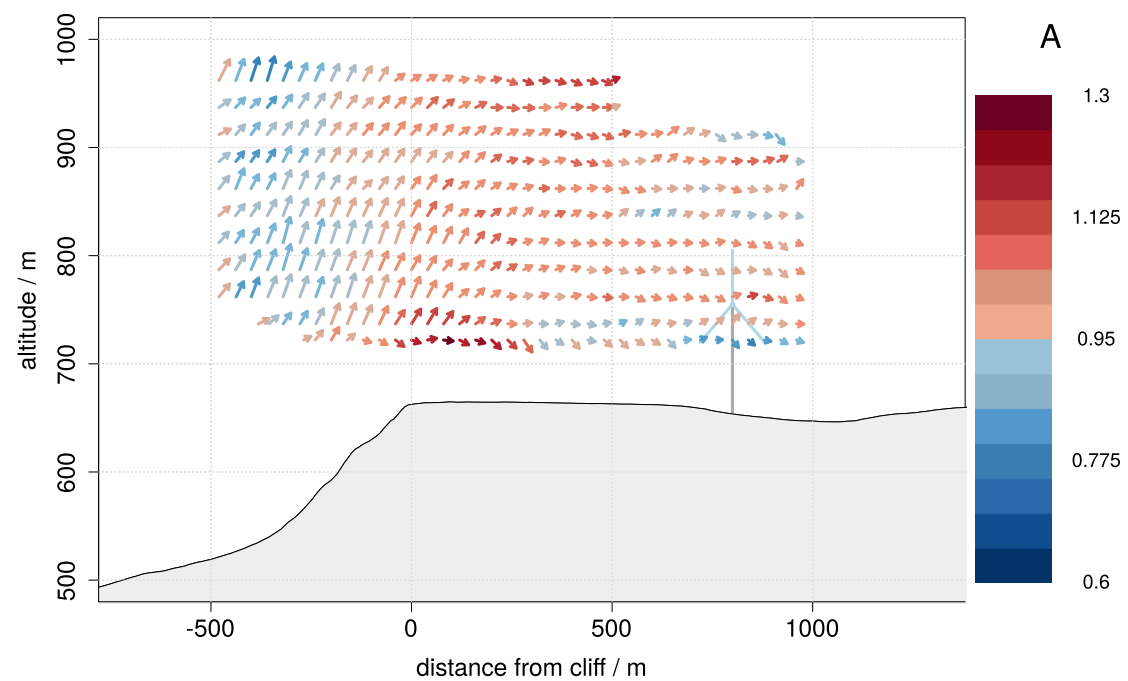

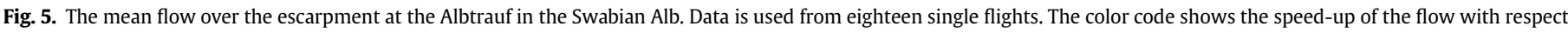
to the mean wind speed of each complete flight. The arrows show the vertical and horizontal wind component. They are scaled according to the aspect ratio of the figure. 


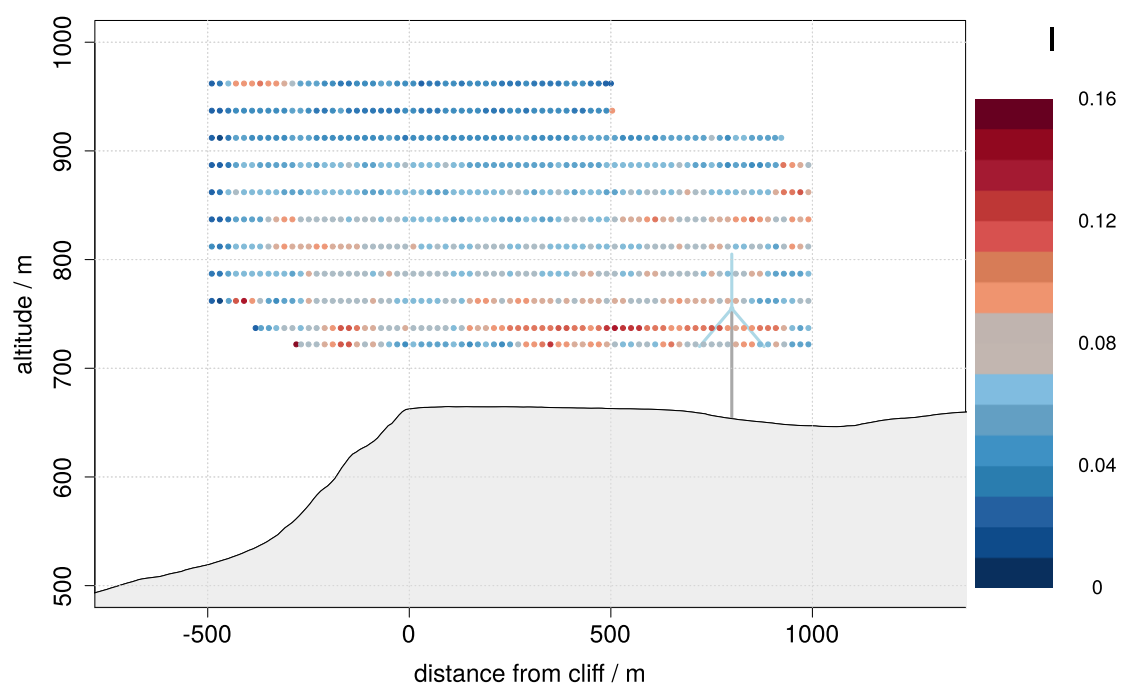

Fig. 6. Field of turbulence intensities, averaged over eighteen individual flights.

dimensional wind vectors. Mean vertical and horizontal wind are scaled according to the aspect ratio of the plot to provide a realistic picture of the flow field. The color code is showing the amplification factor $A$ of the horizontal wind speed with respect to the mean wind speed of the single flights as derived in Eq. (2). There are differences in the extent of the racetracks and the maximum height that was reached during individual flights, which is why the contours of the data points are not in a rectangle, but are a patchwork of all flights. In the center of the figure, data of eighteen flights contribute to the average, while at the borders, less data are available for the average. In grey, the silhouette of a wind turbine at a potential site is shown with a mast height of $100 \mathrm{~m}$ and a rotor diameter of $90 \mathrm{~m}$.

It is obvious that the flow is strongly deflected upward when it hits the escarpment. Vertical wind components up to $5 \mathrm{~m} \mathrm{~s}^{-1}$ are measured over the crest. Necessarily, the flow will accelerate as it is pushed over the hill, which is well captured in the data. The speedup is higher close to the ground, and the highest values are found in the lowest flight level of $60 \mathrm{~m}$. It is evident that the updraught as well as the speed-up of the horizontal wind reaches well up to the highest flight level of $300 \mathrm{~m}$. Approximately 300-500 m downstream of the escarpment, the flow speed decreases again. It is interesting to see that the wind speed decreases most in the lowest levels, which is an indication that after the flow reattaches to the hill, a reattached boundary layer establishes as also described by Sherry et al. [2] and Rokenes and Krogstad [5].

\subsection{Turbulence}

To find the location of the highest turbulence intensities in terms of distance to the escarpment and altitude, Fig. 6 shows a field of calculated turbulent intensities for $40 \mathrm{~m}$ wide bins.

It shows that the highest turbulence intensities are found in the lowest flight levels, at that distance to the escarpment where the flow starts to decelerate. In those regions where the highest speedup is found, turbulence intensity is low.

\subsection{Shear}

Depending on the distance to the escarpment the mean vertical wind profile can have a significantly different shape. Exemplarily, three 100-m wide regions - directly at the edge of the escarpment, $400 \mathrm{~m}$ downstream and $800 \mathrm{~m}$ downstream - have been used in Fig. 7 to show the averaged, normalized vertical wind profile from

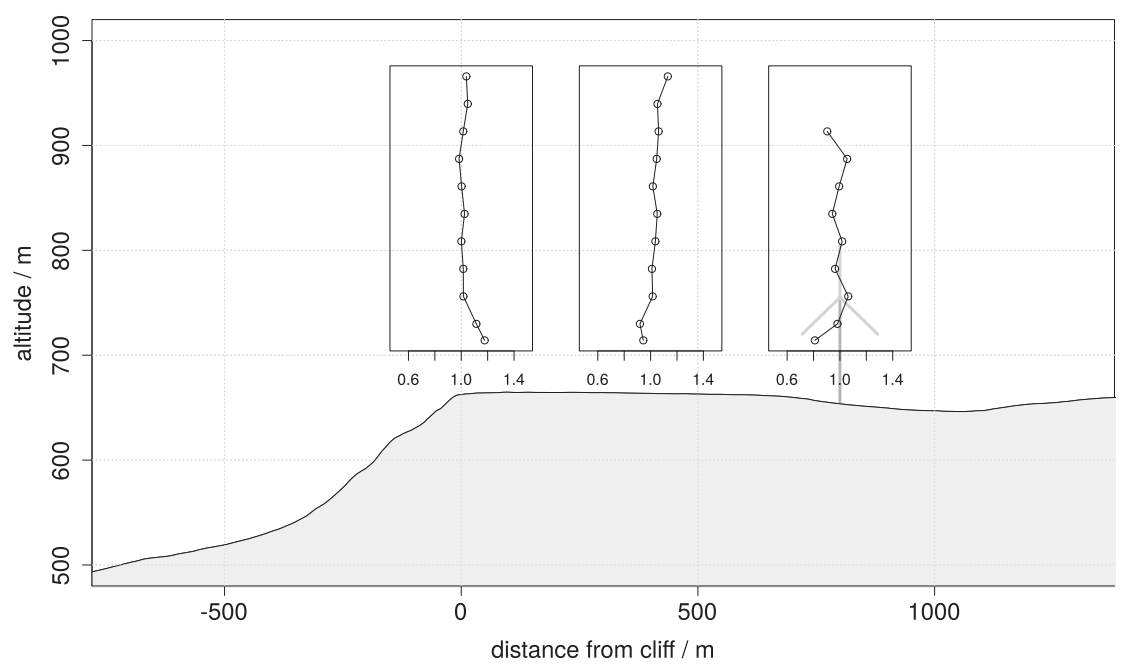

Fig. 7. Averaged and normalized shear profiles of the average flow over the Albtrauf at three distances from the crest: $0 \mathrm{~m}, 400 \mathrm{~m}$ and $800 \mathrm{~m}$. 
the flow field in Fig. 5.

The wind profile over the escarpment edge is strongly affected by the speed-up in the lowest heights, manifesting in negative shear in the rotor area of potential wind turbines at this location. In $400 \mathrm{~m}$ distance to the escarpment, the flow in the lowest levels is still affected by the flow distortion over the escarpment. For the given measurement this results in almost zero shear. In $800 \mathrm{~m}$ distance, a wind profile much more similar to a logarithmic wind profile - as can be found in neutral stratifications over flat terrain is found, with positive shear in the rotor area.

\section{Discussion}

The results that are presented in this study show that even in a highly complex terrain regarding the orography and changes of roughness lengths, some typical features of a flow over a forwardfacing step can still be found. The strong vertical winds over the escarpment are a significant feature of the location, and directly over the crest the wind vector can easily be inclined up to $30^{\circ}$. It however also shows that these updraughts are limited to regions upstream and at most $300 \mathrm{~m}$ downstream the crest. The speed-up over the escarpment could be captured with the RPA in all heights that are relevant for state of the art wind-energy production. The highest values of up to 1.3 are found in the lowest flight levels. It has to be assumed that the maximum of the speed-up is even closer to the escarpment, in a region that was not sampled with the RPA. The actual value of the flow speed-up can be higher compared to the upstream wind, since the reference value that was chosen in this study is the average of the wind speeds in the flight area. The extent of the separation bubble and recirculation zone of the flow can only be guessed from the data. At the lowest flight level of $60 \mathrm{~m}$, negative vertical wind components are found, which are an indication that the recirculation zone starts here. The strong turbulence intensity immediately downstream this region - approximately $500 \mathrm{~m}$ downstream the crest - is in favour of this assumption. A straight forward comparison to the experiments with rather simple geometries as done by Emeis et al. [4], Sherry et al. [2] and Bowen and Lindley [3] is difficult, since the terrain at the Albtrauf does not feature a constant slope and it is unclear how a proper scaling height should be defined. The shear profiles that are shown in Sect. 4.3 fit well with findings of Rokenes and Krogstad [5] in wind tunnel test cases with constant forward-facing slopes. The speed up over the escarpment in these cases lead to a negative shear close to the crest, and reattachment of the flow several multiples of the escarpment height downstream of the flow. In our case, the reattachment is assumed to happen not earlier than $700 \mathrm{~m}$ downstream the crest.

\section{Conclusion}

In this study, an experiment is described which was designed to measure the flow field over an escarpment with small remotelypiloted aircraft. For eighteen flights in similar wind conditions, an average flow field was calculated. The experiment shows that with this technique, detailed in-situ data can be obtained as it has not been possible before. The results of this experiment can help to validate results from CFD simulations and wind tunnel experiments that are currently set up for the experiment location. Siting of a WEC in the investigated area can benefit from the measurements, as it shows that vertical wind components do not seem to be critical at $300 \mathrm{~m}$ and further downstream of the escarpment, but increased turbulence intensity due to the separation of the flow can be found up to $1 \mathrm{~km}$ downstream and can lead to increased loads on the turbine. Special designs of wind-energy converters could possibly make use of the strong vertical winds and speed-up over the escarpment. Several lessons have been learned during the experiment, and ideas for future work have come up:

- So far, the study has focussed on the main wind direction. A detailed investigation of the flow field for different wind directions can give more insight into the uncertainties of the wind potential of possible WEC sites.

- In order to investigate the separation bubble and recirculation zone, flights at lower heights are necessary, which do not need to reach over the escarpment and thus can be performed without losing sight to the RPA.

- A simultaneous vertical profile in the undisturbed upstream flow for every measurement flight could be helpful for a better scaling of the flow speed-up. These vertical profiles will be essential for the initialisation of a CFD model of the flow at the test site.

- Multiple RPA measuring at the same time and at different levels over the escarpment could capture a more instantaneous snapshot of the flow field.

- So far, only near neutral thermal stratification has been investigated. A detailed analysis of the impact of different stabilities on the flow field should be carried out.

Currently, more campaigns and projects regarding the flow over the Albtrauf are planned. The site is considered for the deployment of a modern wind energy test field, with several more meteorological towers, and two WEC with full access to data and control of the machine for the researchers. The RPA as a flexible tool will presumably play an important role in the upcoming research.

\section{Acknowledgement}

The projects "Lidar complex" (grant number 0325519) and "KonTest" (grant number 0325665) are funded by the Federal Ministry for Economic Affairs and Energy based on a decision of the German Bundestag. A digital elevation model was used under the license of @Landesamt für Geoinformation und Landentwicklung Baden-Württemberg, www.lgl-bw.de, Az::2851.9-1/19 for all shown terrain data. We want to thank the safety pilot Maximilian Ehrle, Christoph Lichtmannegger and Alexander Rautenberg for their great job in handling take-offs and landings in challenging wind and weather conditions.

\section{References}

[1] I. Lütkehus, H. Salecker, Onshore wind energy potential in Germany, DEW Mag. 43 (2013) 23-28.

[2] M. Sherry, D. Jacona, J. Sheridan, An experimental investigation of the recirculation zone formed downstream of a forward facing step, J. Wind Energy Ind. Aerodyn. 98 (12) (2010) 888-894.

[3] A. Bowen, D. Lindley, Measurement of the mean wind flow over various escarpment shapes, in: Fifth Australasian Conference on Hydraulics and Fluid Mechanics, 7-9 December, 1974, Christchurch, New Zealand, 1974.

[4] S. Emeis, H.P. Frank, F. Fiedler, Modification of air flow over an escarpment results from the hjardemål experiment, Boundary-Layer Meteorol. 74 (1-2) (1995) 131-161, http://dx.doi.org/10.1007/BF00715714.

[5] K. Rokenes, P.-A. Krogstad, Wind tunnel simulation of terrain effects on wind farm siting, Wind Energy 12 (4) (2009) 391-410, http://dx.doi.org/10.1002/ we.310.

[6] F. Bingöl, J. Mann, D. Foussekis, Conically scanning lidar error in complex terrain, Meteorol. Z. 18 (2) (2009) 189-195, http://dx.doi.org/10.1127/09412948/2009/0368.

[7] J. Mann, J.-P. Cariou, M.S. Courtney, R. Parmentier, T. Mikkelsen, R. Wagner P. Lindelöw, M. Sjöholm, K. Enevoldsen, Comparison of 3d turbulence measurements using three staring wind lidars and a sonic anemometer, in: 14th International Symposium for the Advancement of Boundary Layer Remote Sensing, 23-25 June 2008, Risø National Laboratory, DTU, Denmark, 2008.

[8] T. Mikkelsen, J. Mann, M. Courtney, M. Sjöholm, Windscanner: 3-d wind and turbulence measurements from three steerable doppler lidars, in: 14th International Symposium for the Advancement of Boundary Layer Remote Sensing, 23-25 June 2008, Risø National Laboratory, DTU, Denmark, 2008. 
[9] F.C. Fuertes, G.V. Iungo, F. Porté-Agel, 3d turbulence measurements using three synchronous wind lidars: validation against sonic anemometry, J. Atmos. Ocean. Technol. 31 (7) (2014) 1549-1556, http://dx.doi.org/10.1175/ JTECH-D-13-00206.1.

[10] A.C. van den Kroonenberg, T. Martin, M. Buschmann, J. Bange, P. Vörsmann, Measuring the wind vector using the autonomous mini aerial vehicle $\mathrm{M}^{2} \mathrm{AV}$, J. Atmos. Ocean. Technol. 25 (2008) 1969-1982.

[11] S. Martin, F. Beyrich, J. Bange, Observing entrainment processes using a small unmanned aerial vehicle: a feasibility study, Boundary-Layer Meteorol. 150 (3) (2014) 449-467, http://dx.doi.org/10.1007/s10546-013-9880-4.

[12] N. Wildmann, M. Hofsäß, F. Weimer, A. Joos, J. Bange, Masc - a small remotely piloted aircraft (RPA) for wind energy research, Adv. Sci. Res. 11 (2014) 55-61, http://dx.doi.org/10.5194/asr-11-55-2014.

[13] N. Wildmann, G. Rau, J. Bange, Observations of the early morning boundarylayer transition with small remotely-piloted aircraft, Boundary-Layer Meteorol. 157 (3) (2015) 345-373, http://dx.doi.org/10.1007/s10546-015-0059-Z.

[14] D. Herr, D. Heidenreich, How turbulent winds abuse wind turbine drivetrains, Windpower Engineering and Development, http://www.windpowerengineering.com/design/how-turbulent-wind-abuse-wind-turbine-drivetrains/, last access: 5 July 2015

[15] G. Giebel, U. Schmidt Paulsen, J. Bange, A. la Cour-Harbo, J. Reuder, S. Mayer A. van der Kroonenberg, J. Mølgaard, Autonomous Aerial Sensors for Wind Power Meteorology - a Pre-project, Danmarks Tekniske Universitet, Ris
Nationallaboratoriet for Bæredygtig Energi, 2012.

[16] J. Reuder, M.O. Jonassen, First results of turbulence measurements in a wind park with the small unmanned meteorological observer SUMO, in: Selected Papers from Deep Sea Offshore Wind Ramp Conference, Vol. 24, Trondheim, NO, 2012, pp. 176-185, http://dx.doi.org/10.1016/j.egypro.2012.06.099.

[17] B. Subramanian, N. Chokani, R.S. Abhari, Full scale hawt: structure of near wake turbulence measured with instrumented UAV, in: EWEA 2012 Conference Proceedings, Copenhagen, DK, 2012.

[18] N. Wildmann, M. Mauz J. Bange Two fast temperature sensors for probing of the atmospheric boundary layer using small remotely piloted aircraft (RPA), Atmos. Meas. Tech. 6 (8) (2013) 2101-2113, http://dx.doi.org/10.5194/amt-62101-2013.

[19] N. Wildmann, S. Ravi, J. Bange, Towards higher accuracy and better frequency response with standard multi-hole probes in turbulence measurement with remotely piloted aircraft (RPA), Atmos. Meas. Tech. 7 (4) (2014) 1027-1041, http://dx.doi.org/10.5194/amt-7-1027-2014.

[20] N. Wildmann, F. Kaufmann, J. Bange, An inverse-modelling approach for frequency response correction of capacitive humidity sensors in abl research with small remotely piloted aircraft (RPA), Atmos. Meas. Tech. 7 (9) (2014) 3059-3069, http://dx.doi.org/10.5194/amt-7-3059-2014.

[21] The International Electrotechnical Commission, Wind Turbines - Part 1: Design Requirements, IEC, 2005, pp. 61400-61401. Tech. Rep. 